\title{
An Approach on Analytical Modeling of Composite Casing for Space Applications
}

\author{
Dr. G. Srinivasa Gupta ${ }^{1}$, Dr. N. Kiran Kumar ${ }^{2}$, Dr. K. Ajay Kumar ${ }^{3}$ \\ $\left({ }^{1,2,3}\right.$ Mechanical Department, VNR Vignana Jyothi Institute of Engineering \& Technology, India $)$
}

\begin{abstract}
In this approach a composite cylindrical casing has been modeled using Analytical method from fundamentals of three dimensional stress equilibrium equations with boundary conditions prevailed in space applications \& compatibility conditions of requirement. A FRP composite made of E-glass fiber with phenolic resin is selected for solving the developed model. Four phase model is used for the analysis. The stress distribution at various locations of fiber coating as well as coating resin interfacing is evaluated using 'Mathematica' software for solving analytical model. Comparisons of various stresses in phases have been carried out at different conditions of temperature and moisture combinations for the selected composite material. The results are validated with allowable values of corresponding strength of each phase and it has also been estimated that the conditions under which the composite material can be used for the application.
\end{abstract}

Keywords: E-glass fiber, Mathematica, coating, moisture, phenolic resin, temperature.

\section{Introduction}

Rocket motor case plays an important role in the proper working of rocket. The selection of materials which have a high specific strength with minimum structural weight, high temperature resistance, moisture resistance is an important consideration in the design of rocket motor case [1-3]. A polymer matrix fiber reinforced composite is made of E-glass fiber with phenolic resin has been chosen for the analysis because of its high specific strength, light weight, structural capability and in space vehicle applications. The four phase model is adopted in which fiber, low modulus resin (coating), high modulus resin and outer composite are four phases respectively. The properties of outer composite phase have been estimated using rule of mixture relations [4]. Analysis was carried out at different temperature and moisture condition prevailed in the rocket motor casing applications [5] to find out the stress distribution within the phases of composite lamina and also interface of different phases with the help of mathematical tool called Mathematica software. The procedures will be developed to meet the design requirement for preventing failures, light weight, to maintain safety in operation.

\section{Mathematical Modeling}

A four phase model as shown in Fig. 1 is taken for developing the equations to find out the stress distribution pattern. A micro stress analysis is carried out for composite material to find out the stress distribution pattern using Mathematica. The various layers of composite are shown in Fig. 1

1. Outermost cylinder (Overall composite)

2. Matrix (High modulus resin).

3. Low modulus Coating (Thin layer between fiber and matrix).

4. Fiber (Innermost cylindrical shape).

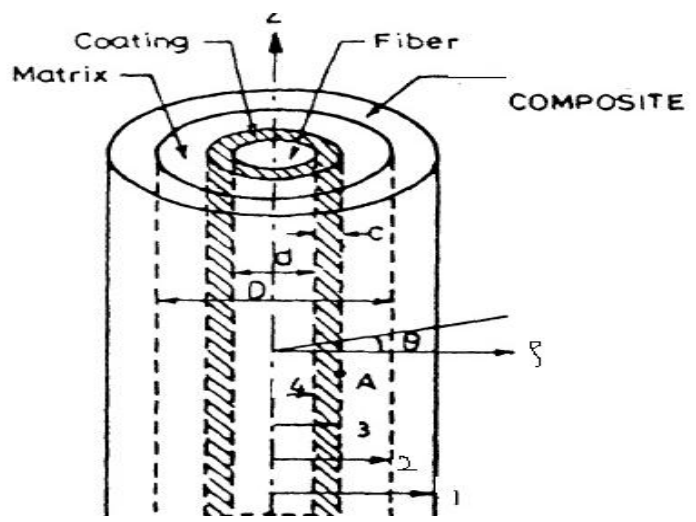

Figure 1: Representation of four phase model [5] 


\subsection{ASSUMPTIONS}

- Fibers are considered as regularly spaced and perfectly aligned and bonded.

- No voids exist in any of the four phases.

- Perfect bond exists at the interface among the phases

- Swelling strains are independent of temperature in all phases.

- Fiber material is impervious to moisture absorption.

\subsection{FUNDAMENTAL EQUILIBRIUM EQUATIONS USED FOR THE ANALYSIS [4]}

$$
\begin{aligned}
& \frac{1}{\rho} \frac{d\left(\rho \sigma_{\rho \rho}^{k}\right)}{d \rho}+\frac{1}{\rho} \frac{d\left(\rho \sigma_{\rho \theta}^{k}\right)}{d \theta}+\frac{d\left(\rho \sigma_{\rho z}^{k}\right)}{d z}-\frac{\sigma_{\theta \theta}^{k}}{\rho}=0 \\
& \frac{1}{\rho^{2}} \frac{d\left(\rho^{2} \sigma_{\theta \rho}^{k}\right)}{d \rho}+\frac{1}{\rho} \frac{d\left(\rho \sigma_{\theta \theta}^{k}\right)}{d \theta}+\frac{d\left(\sigma_{\theta z}^{k}\right)}{d z}=0 \\
& \frac{1}{\rho} \frac{d\left(\rho \sigma_{z \rho}^{k}\right)}{d r}+\frac{1}{\rho} \frac{d\left(\rho \sigma_{z \theta}^{k}\right)}{d \theta}+\frac{d\left(\sigma_{z z}^{k}\right)}{d z}=0
\end{aligned}
$$

\subsection{STRESS STRAIN RELATIONS}

Application of boundary conditions and compatibility conditions in the equation (1) and its simplification results the various stresses in terms of stiffness, thermal and moisture expansion coefficients of various phases, these equations can be written as

$$
\begin{aligned}
& \sigma_{\mathrm{rr}}(\mathrm{n})=\mathrm{c}_{11}(\mathrm{n}) * \mathrm{e}_{\mathrm{rr}}(\mathrm{n})+\mathrm{c}_{12}(\mathrm{n}) * \mathrm{e}_{\mathrm{yy}}(\mathrm{n})+\mathrm{c}_{13}(\mathrm{n}) * \mathrm{e}_{\mathrm{zz}}(\mathrm{n})-\gamma_{1}(\mathrm{n}) \mathrm{T}_{\mathrm{n}}-\lambda_{1}(\mathrm{n}) \mathrm{m}_{\mathrm{n}} \\
& \sigma_{\mathrm{yy}}(\mathrm{n})=\mathrm{c}_{12}(\mathrm{n}) * \mathrm{e}_{\mathrm{rr}}(\mathrm{n})+\mathrm{c}_{11}(\mathrm{n}) * \mathrm{e}_{\mathrm{yy}}(\mathrm{n})+\mathrm{c}_{13}(\mathrm{n}) * \mathrm{e}_{\mathrm{zz}}(\mathrm{n})-\gamma_{1}(\mathrm{n}) \mathrm{T}_{\mathrm{n}}-\lambda_{1}(\mathrm{n}) \mathrm{m}_{\mathrm{n}} \\
& \sigma_{\mathrm{zz}}(\mathrm{n})=\mathrm{c}_{13}(\mathrm{n}) * \mathrm{e}_{\mathrm{rr}}(\mathrm{n})+\mathrm{c}_{13}(\mathrm{n}) * \mathrm{e}_{\mathrm{yy}}(\mathrm{n})+\mathrm{c}_{33}(\mathrm{n}) * \mathrm{e}_{\mathrm{zz}}(\mathrm{n})-\gamma_{3}(\mathrm{n}) \mathrm{T}_{\mathrm{n}}-\lambda_{3}(\mathrm{n}) \mathrm{m}_{\mathrm{n}} \\
& \sigma_{\mathrm{yz}}(\mathrm{n})=2 \mathrm{c}_{44}(\mathrm{n}) * \mathrm{e}_{\mathrm{yz}}(\mathrm{n}) \\
& \sigma_{\mathrm{zr}}(\mathrm{n})=2 \mathrm{c}_{44}(\mathrm{n}) * 2 \mathrm{e}_{\mathrm{zr}}(\mathrm{n}) \\
& \sigma_{\mathrm{ry}}(\mathrm{n})=\left(\mathrm{c}_{11}(\mathrm{n})-\mathrm{c}_{12}(\mathrm{n})\right)^{*} \mathrm{e}_{\mathrm{ry}}(\mathrm{n})
\end{aligned}
$$

Where e's with subscripts are strains which are derived from fundamental equations of stress strain relations. $\gamma$ and $\lambda$ are functions of thermal and moisture expansion coefficients [6].

Due to axisymmetry, the stress components do not depend on circumferential direction i.e., "y direction".

Therefore $\sigma_{\mathrm{yz}}(\mathrm{n})=\sigma_{\mathrm{zr}}(\mathrm{n})=\sigma_{\mathrm{ry}}(\mathrm{n})=0$

From Equations (1) and (2) the stress distribution pattern is estimated among and in the phases using Mathematica at temperature (T) and moisture (M\%) combinations as mentioned in the table as given below:

$\mathrm{T}=90^{\circ} \mathrm{C}, \quad \mathrm{M}=0 \%$,

$\mathrm{T}=90^{\circ} \mathrm{C}, \quad \mathrm{M}=3 \%$,

$\mathrm{T}=90^{\circ} \mathrm{C}, \quad \mathrm{M}=5 \%$,

$\mathrm{T}=150{ }^{\circ} \mathrm{C}, \mathrm{M}=0 \%$,

$\mathrm{T}=150^{\circ} \mathrm{C}, \mathrm{M}=3 \%$,

$\mathrm{T}=150^{\circ} \mathrm{C}, \mathrm{M}=5 \%$

which are minimum operating conditions prevailed in composite material applications [7].

\section{Results And Discussions}

The stress distribution of various phases in the composite mentioned in Fig. 1 are discussed for $90{ }^{\circ} \mathrm{C}$ and $150{ }^{\circ} \mathrm{C}$ at $0 \%, 3 \%$ and $5 \%$ moisture conditions along radial (r), axial (z) and angular (y) directions are described in Fig.2 to Fig.7. 
IOSR Journal of Mechanical and Civil Engineering (IOSR-JMCE)

e-ISSN: 2278-1684, p-ISSN : 2320-334X

PP 28-32

www.iosrjournals.org

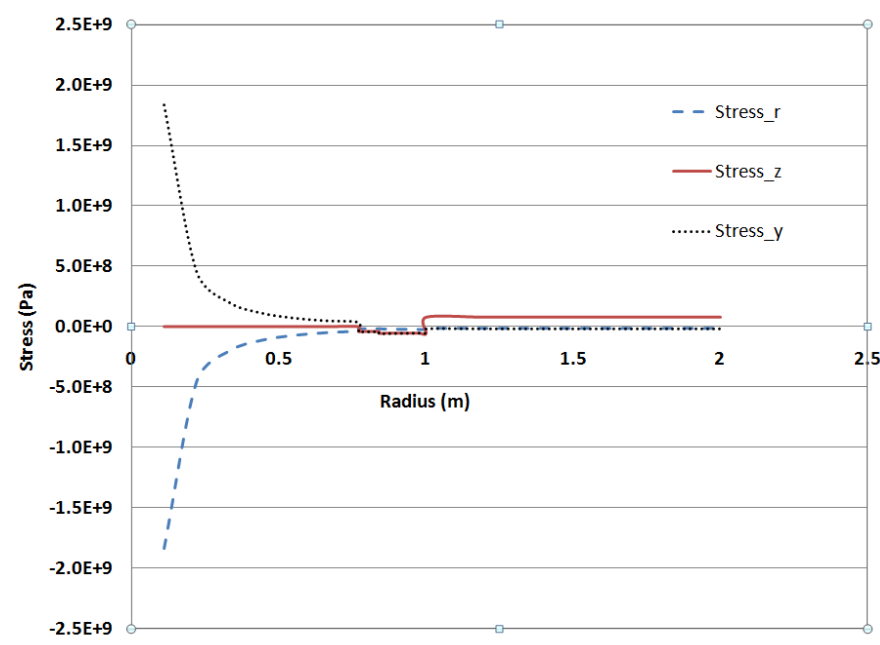

Figure.2: Stress distribution at $90{ }^{\circ} \mathrm{C}, 0 \%$ Moisture

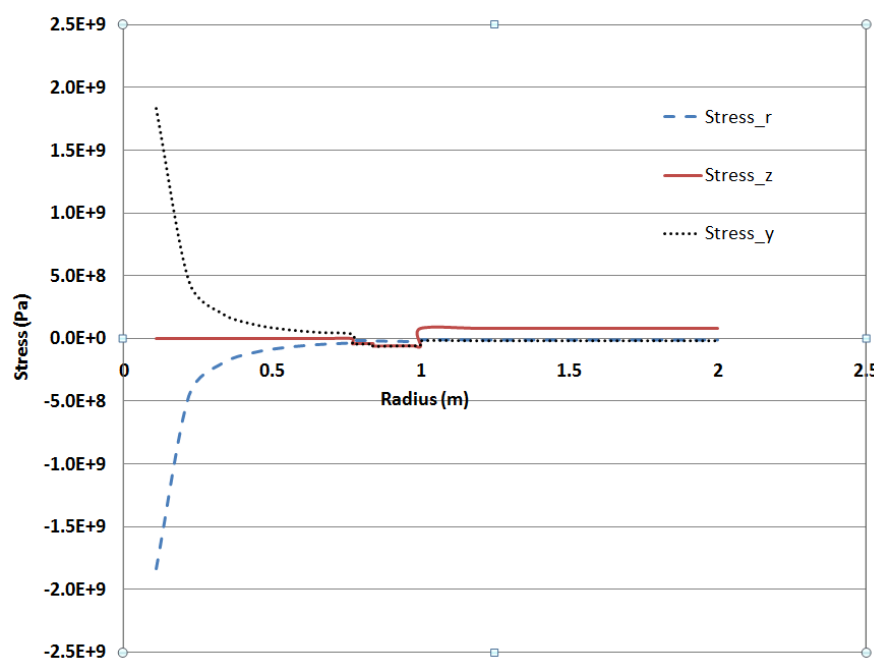

Figure.3: Stress distribution at $90{ }^{\circ} \mathrm{C}, 3 \%$ Moisture

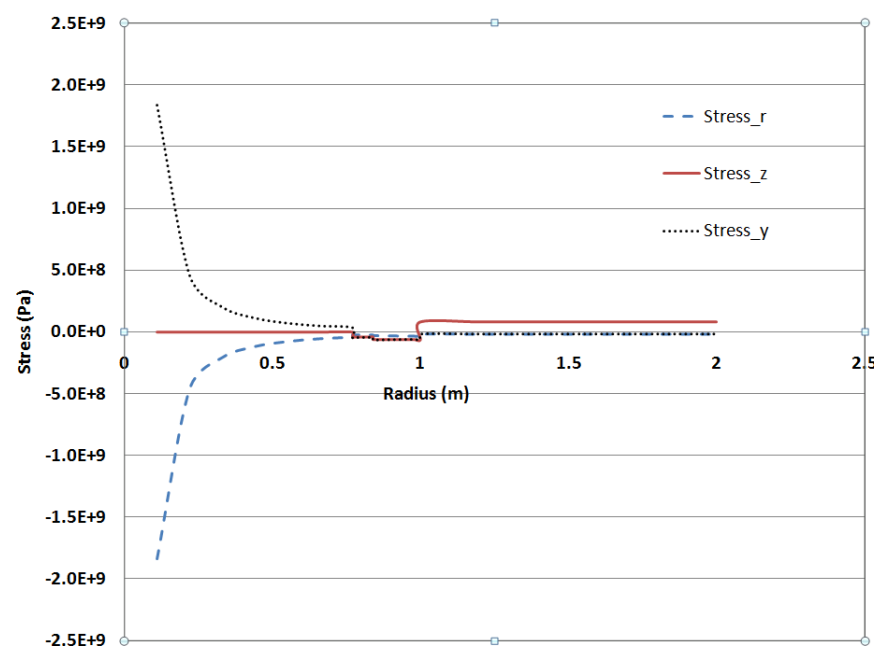

Figure.4: Stress distribution at $90{ }^{\circ} \mathrm{C}, 5 \%$ Moisture 


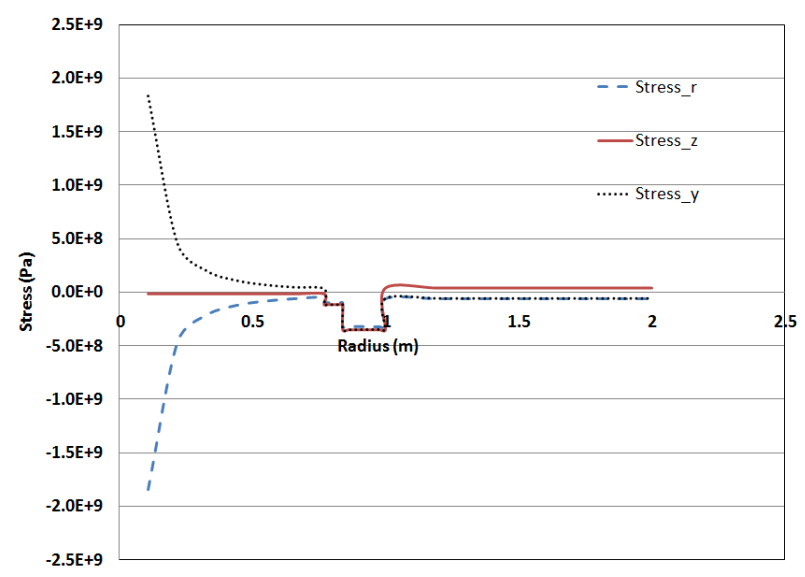

Figure.5: Stress distribution at $150{ }^{\circ} \mathrm{C}, 0 \%$ Moisture

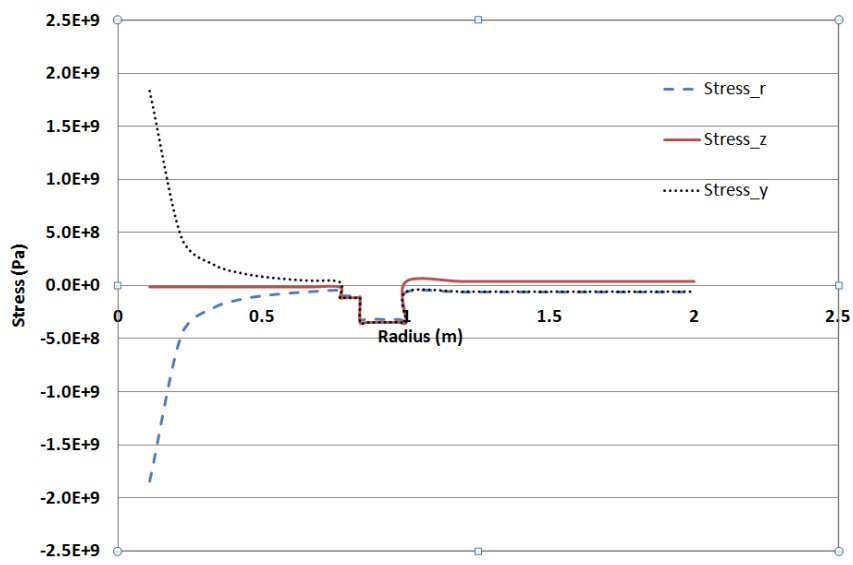

Figure.6: Stress distribution at $150{ }^{\circ} \mathrm{C}, 3 \%$ Moisture

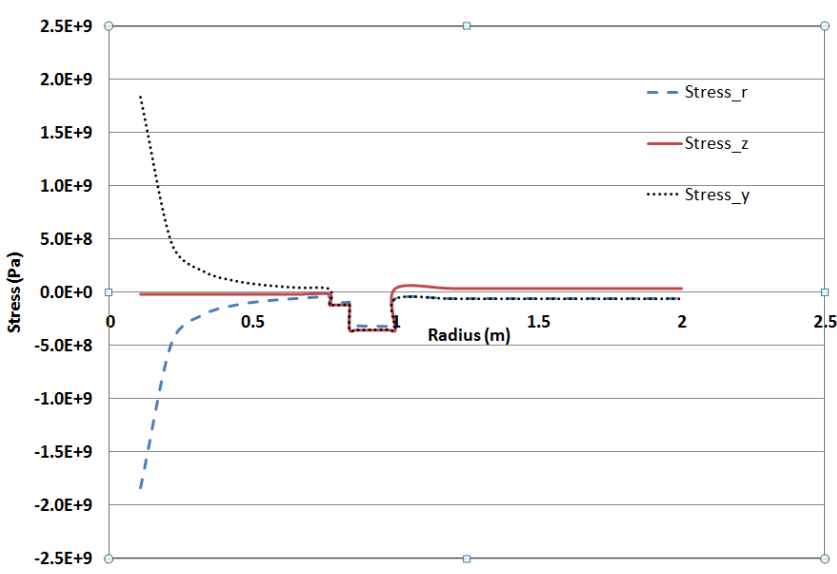

Figure.7: Stress distribution at $150{ }^{\circ} \mathrm{C}, 5 \%$ Moisture

From Fig.2 to Fig.7, it was observed that the angular stress in the fiber phase is tensile and radial stress is compressive with equal magnitudes. But there is no axial stress found in the fiber phase as there is no direct external load. In the coating and matrix phases all these stresses are in compressive. While in the outermost composite phase, the radial stress is tensile and other two stresses are in compressive. The same type of stress patterns are found in all phases at both selected temperature and moisture conditions as well as its combination. 


\section{Conclusion}

- It was observed that the angular and radial stresses in the fiber phase are quite opposite in behavior with equal magnitude, whereas no axial stress found in the fiber phase.

- Coating and matrix phases are exhibiting compressive behavior in axial, radial and angular directions. But the composite phase is exhibiting tensile behavior in the axial direction and compressive behavior in angular and radial directions.

- With the increment of temperature or simultaneously the temperature and the moisture percentage increase the magnitude of all these stresses in coating as well as matrix phases retaining the same compressive nature.

- It has been found that for the composite phase there is an increment in magnitude of radial and angular stresses retaining the compressive nature at the same time the magnitude of axial stress is drop down considerably with tensile in nature.

\section{References}

[1]. Shaik Shaheen, Dr. G. Srinivasa Gupta: "Design and Analysis of Carbon-Epoxy composite Rocket Motor Casing", International Journal of Innovative Research in Science, Engineering and Technology, Vol. 4, pp. 7397-740, 2015.

[2]. P. N. V. Harinath, Dr. G. Srinivasa Gupta: “Experimental Investigation on Techniques to Improve Properties in Ablative Liner", International Journal of Science and Research, Vol. 1, pp. 131-134, 2014.

[3]. P. Mahesh Babu, G. Bala Krishna and B. Siva Prasad: "Design and Analysis of Solid Rocket Motor Casing for Aerospace Application"s, International journal of current engineering and technology, Vol. 5, pp. 1947-1954, 2015.

[4]. Jones, R. M. Mechanics of Composite Materials, CRC Press, 1998.

[5]. P. C. Upadhyay, K. Guru Murthy and D. W. Lyons: "Stress field in Coated Continous Fiber-Reinforced Polymeric Composite Due to Hygrothermal Loading", Journal of Reinforced Plastics and Composites, vol. 15, pp. 619-650, 1996.

[6]. Rajamani, Dr. G. Srinivasa Gupta: "Design and Analysis of Rocket Motor Bolted Joint for Enhanced Strength", International Journal of Innovative Research in Science, Engineering and Technology, Vol. 4, pp. 6396-6406, 2015.

[7]. G. Avinash, Dr. S. Rama Krishna, Narendra kumar shrivastava: "Design and Analysis of Composite Rocket Motor Casing”, International journal of emerging technology and advanced engineering, Vol.4, pp. 231-236, 2014. 